\title{
El decálogo fundacional de la teoría general del costo. Un replanteo necesario ${ }^{(1)}$
}

\author{
Laura G. García \\ Prof. "Costos y Gestión" y Sistemas de información \\ Gerencial", FCE, UNL.
}

\begin{abstract}
"La ciencia nunca persigue la ilusoria meta de que sus respuestas sean definitivas, ni siquiera probables; antes bien, su avance se encamina hacia una finalidad infinita -y sin embargo alcanzable: la de descubrir incesantemente problemas nuevos, más profundos y más generales, $y$ de sujetar nuestras respuestas (siempre provisorias) a contrastaciones constantemente renovadas y cada vez más rigurosas." Karl Popper, 1962.
\end{abstract}

\section{La Teoría General}

La necesidad de rescatar la problemática referida a la conceptualización del fenómeno costo surge a partir de la importancia de otorgarle precisión al mismo a fin de alcanzar la rigurosidad requerida por una teoría científica.

Su problemática y su significado no se limitan, en modo alguno, a la definición del mismo. Analizar este problema abarca una multiplicidad de aspectos que se requieren para su comprensión y que no han sido tratados suficientemente por la doctrina o, directamente, no han sido abordados por ella.

La Teoría General del Costo surge en el marco de la Universidad de Buenos Aires como respuesta a la ausencia de fundamentos teóricos en todo lo relativo a determinación y medición de los costos. Aunque las ideas sobre su formación pueden ubi-

carse durante los años ochenta, su producción formal comienza a difundirse en la década siguiente.

Su construcción procura otorgar al fenómeno costo una trascendencia que explique la variedad de elementos que se requieren para la comprensión del mismo y se define a sí misma como el conjunto de conocimientos que aspira a concentrar los principios que explican, dan fundamento y respaldo a las técnicas de costeo.

Si bien es un enfoque que podría considerarse en alguna medida reciente, constituye un referente importante a nivel nacional, e incluso internacional, en lo que a análisis teórico refiere.

Su objetivo principal consiste inicialmente en resaltar los elementos esenciales intrínsecos al fenómeno productivo, verificables en lo general an-

(1) Adaptación de la tesis de maestría "El concepto de costo desde la Teoría General. Análisis de los principios fundamentales sobre los que se sustenta su construcción", Maestría en Administración de Empresas, FCE-UNL, 2005. 
tes que la descripción exclusiva de las técnicas, las que son, en sí mismas, eventuales o de carácter circunstancial.

Para alcanzar este propósito, y aspirando a constituirse en una teoría, construye un esquema explicativo con la debida coherencia interna bajo la hipótesis de que los hechos que se presumen su objeto de estudio son, esencialmente, de naturaleza económica.

Su desarrollo se orienta a la construcción de un conjunto ordenado de conocimientos que expliquen y respalden las técnicas de gestión relativas a la problemática de los costos y también de los resultados de las organizaciones económicas, excediendo las transacciones en las que la organización actúa simultáneamente con agentes externos a la misma y focalizando la atención en las transformaciones internas que en ellas se producen.

Su gran desafío consiste, además de continuar avanzando en la sistematización de la teoría propiamente dicha, en construir esquemas de aplicación general que logren, simultáneamente, ser compatibles con su perspectiva y ser útiles a los niveles gerenciales para el proceso de toma de decisiones.

Por lo tanto, se encuentra asentada sobre tres pilares básicos: un pilar en la gestión, a partir de la cual se detectan los problemas de la realidad empresarial, un pilar en los sistemas de información, que permiten crear las herramientas para la solución de problemas y un pilar en la economía, que provee los principios generales implícitos en las herramientas empleadas.

\section{El decálogo}

En el año 1992, durante el período de gestación de la Teoría General del Costo, los Profesores Enrique Cartier y 0 scar 0 sorio presentaron la misma en un evento científico iberoamericano a través de una ponencia denominada "Teoría General del Costo. Un marco necesario".
Allí, ellos manifestaron su posición doctrinaria respecto de la subordinación de la contabilidad de costos hacia la ciencia económica y expusieron en forma de decálogo los aspectos más destacados de la Teoría General del Costo y de los que la misma debía ocuparse.

En el detalle de estas pautas se resumían los aportes y avances más significativos alcanzados hasta ese momento por distintas investigaciones en la materia en vistas a la construcción de un cuerpo orgánico.

La Teoría General ha superado actualmente en su desarrollo los aspectos mencionados destacándose, principalmente, los referidos a categorizaciones de factores y de costos y consideraciones sobre modelos y técnicas de costeo, por lo que el decálogo mencionado, a nuestro entender, ha quedado reducido a los aspectos fundamentales implicados únicamente en la conceptualización del fenómeno costo a partir de los cuales es posible derivar, con posterioridad, otros análisis complementarios.

Por esta razón es que en el desarrollo de este trabajo de investigación se tratan los principios sobre los que se sustenta la construcción del concepto de costo desde la Teoría General a partir del análisis de cada una de las diez temáticas incluidas originalmente en el decálogo señalado.

El objetivo principal consiste en realizar una interpretación crítico-analítica que permita una recreación y adecuación del marco teórico de la Teoría General profundizando acerca de la validez de algunos de sus postulados básicos a fin de reformular 0 adaptar, en su caso, dichas proposiciones.

Por último, corresponde agregar que los autores del decálogo indicado constituyen los "fundadores" de la Teoría General en el ámbito nacional. A su vez, la Teoría General ha tenido en cuenta para su elaboración la referencia permanente de autores europeos tales como Erich Schneider, Aldo Spranzi y Moisés García García, entre los más destacados. 


\section{El replanteo}

Las conclusiones del trabajo se resumen en el concepto de costo como "valor de los factores considerados necesarios en una operación de producción para la obtención de un objetivo productivo" y el replanteo del decálogo original.

En el cuadro que se expone a continuación se visualizan ambos decálogos, tanto el propuesto como el original planteado por la Teoría, en forma comparativa. Allí, cada ítem del nuevo decálogo se presenta, en su caso, conjuntamente con su correspondiente ítem anterior a efectos de visualizar las diferencias entre ellos con las respectivas conclusiones complementarias.

\begin{tabular}{lll}
\hline Decálogo original & Decálogo propuesto \\
\hline 1 & El costo como fenómeno físico antes que monetario. & $\begin{array}{l}\text { El costo como fenómeno físico- económico antes que } \\
\text { monetario. }\end{array}$
\end{tabular}

El costo es un fenómeno que entraña, intrínsecamente, un aspecto técnico y un aspecto económico en forma concomitante. Descartamos la consideración exclusivamente física del mismo y la expresión "antes que monetario" complementa su propiedad de hecho económico mixto en su carácter no unívoco.

$2 \quad$ El componente físico y el componente monetario del

El componente físico y el componente de valor del costo. costo.

El componente físico del costo es el elemento representativo de su aspecto técnico y el componente de valor de su aspecto económico. El componente monetario no existe como tal en la perspectiva adoptada.

La "monetización" del costo como necesidad instrumental.

Monetizar el costo no es una necesidad instrumental. Sí es una necesidad ontológica representar su valor económico. Por lo tanto, este ítem del decálogo anterior desaparece sin sustituirse dado que la esencialidad enunciada se encuentra contenida en los dos primeros.

La explicitación de la Ecuación General del Costo instrumentaliza ambos componentes y dada su trascendencia en la posterior determinación de los costos merece ser destacada en un punto específico.

$4 \quad$ El concepto de costo y su extensión.

Las relaciones de eficiencia como vinculación técnica básica.

La extensión del concepto alcanza a la vinculación básica que relaciona objetivos productivos con factores de sacrificio necesario para su obtención, la que significa la relación de eficiencia desde el aspecto técnico y el valor agregado desde el aspecto económico. 


\section{Decálogo original Decálogo propuesto}
$6 \quad$ Los factores del devengamiento de los recursos.
Los factores de influencia de los costos.

Los factores de influencia de los costos explican el comportamiento de los mismos, reconociendo la incidencia no exclusiva de alguno de ellos en el movimiento de las variables implicadas.

7 La necesariedad desde el punto de vista cualitativo. La necesariedad cualitativa de los factores.

La "necesariedad" está referida a los factores de producción que intervienen en un proceso productivo. En su aspecto cualitativo comprende tres alternativas de consideración: variable, directo y completo.

8 La necesariedad desde el punto de vista cuantitativo. La necesariedad cuantitativa de los factores.

El aspecto cuantitativo de la "necesariedad" de los factores comprende dos alternativas: normalizado y resultante.

$9 \quad$ La naturaleza del proceso productivo y las relaciones

La naturaleza del proceso productivo y las relaciones funcionales. funcionales.

Las relaciones objetivas entre factores productivos $y$

las acciones que componen el proceso de producción.

La naturaleza de las relaciones reconocibles en una operación de producción son de carácter funcional (no causal). Esta cualidad alcanza a las relaciones entre acciones, entre factores y el desarrollo de acciones y entre estas y la obtención de objetivos. El "principio de causalidad" no constituye un elemento válido para la explicación real de los hechos productivos.

10 La relatividad del concepto de costo. La relatividad del fenómeno costo.

La relatividad se afirma en la interpretación del fenómeno en sus diferentes manifestaciones. El concepto de costo se encuentra delimitado en su comprensión y extensión. 